\title{
POLA KOMUNIKASI TRANSENDENTAL DALAM KONTEKS PROSESI NGEREH BAGI TAPAKAN BHATARA DI BALI
}

Ida Bagus Putu Supriadi ${ }^{1}$

Universitas Hindu Negeri I Gusti Bagus Sugriwa Denpasar

Abstract

1ibpsihdn2018@gmail.com
This research was designed qualitatively descriptively because the field phenomenon that wanted to be expressed was in the form of subjective experience and knowledge of the informants, then analyzed to obtain intersubjective conclusions. Aims to identify and interpret field data based on the view of transcendental communication. Postpositivistic paradigm with a phenomenological approach to communication. The material object of the procession is ngereh for the monks in Bali, while the formal object is the application of the concept of transcendental communication. The use of qualitative design means that this research emphasizes more on reality with interactive, plural dimensions, and the existence of an exchange of social experiences that can be interpreted individually.

Hinduism (Bali) is a tantrayana religion. All activities of practicing tattwa and morals are in the form of religious events, which use the traditional ritual. One of the religious events, which contain the practice of divinity is the use of statues/pretima in the form of a temple bhatara which is worshiped in temples in Bali and several temples outside Bali. Before becoming a priest, a newly created pretime/barong/rangda, a purification ritual (sacralization) must be carried out to get the panugrahan as a priest's tapakan.

This chilling procession for the bhatara's tread is the object of this research, and four important things have been found. First, at each stage of the ritual a transcendental communication event occurs. Second, the transcendental communication component in the context of the ngereh procession at the bhatara's footprint in Bali includes the procession actors (pengereh) and supernatural/supernatural powers (who act as communicators and communicants alternately). Mantras or sehe that are spoken and mudras that are made mystically (act as messages), as a means of upakara as a yantra or communication medium. Third, the context of transcendental communication that can be identified for the tapakan bhatara is: the context of communication when the mangala/stakeholder/sangging performs the prayascita ceremony. when 
the mangala/stakeholder/sangging performed the ngatep and mintonin ceremonies, and when the mangala/stakeholders/sangging performed the pasupati and ngereh ceremonies. The four effects of transcendental communication include cognitive experience/knowledge, affective experience/knowledge, and behavioral experience/knowledge.

Keywords

Transcendental Communication, The Procession, The Bhatara's Tread

\section{PENDAHULUAN}

Agama Hindu jika diibaratkan sebagai sebuah bangunan, maka komponen bangunan tersebut dapat dilihat kerangkanya, yang terdiri dari tiga unsur, yakni fondasi, dinding, dan atap. Nala (2012) dalam Murddha Agama Hindu menjelaskan tiga kerangka dasar agama Hindu dengan mengutip lontar Sundarigama, yang memperkenalkan istilah : Agama, Ugama, dan Igama. Agama sama dengan ambek atau susila sebagai fondasi agama Hindu. Ugama sama dengan ulah yakni perilaku menjalankan acara agama, sebagai dinding bangunan agama Hindu, dan Igama sama dengan idep atau tattwa sebagai atap bangunan agama Hindu. Ketiganya merupakan satu kesatuan yang utuh, ketiadaan salah satu unsur dapat menimbulkan disfungsi dalam praktik keagamaan sehari-hari.

Ngurah, (2011) menyatakan, dari ketiga unsur bangunan agama itu, dinding bangunan agamalah yang paling tampak menonjol. Karena itu acara/upacara menjadi bentuk formal pengamalan agama dalam kehidupan sehari-hari. Walapun demikian acara/upacara mutlak berlandaskan ajaran susila dan diayomi atau dipayungi ajaran tattwa. Acara agama dalam pengertian yang lebih luas disebut yajna (Nala, 2012).

Agama Hindu (Bali) adalah agama yang bercorak tantrayana (Jiwa Atmaja (Ed.,2007). Hampir semua aktivitas pengamalan tattwa dan susila dalam bentuk acara agama, menggunakan upakara bebantenan (Putra, 2014). Salah satu acara agama, yang mengandung pengamalan ajaran ketuhanan adalah penggunaan arca/pretima dalam bentuk tapakan bhatara yang dipuja di pura-pura di Bali dan beberapa pura di luar Bali (Jiwa Atmaja,Ed.,2007). Sebelum menjadi tapakan bhatara., pretime/barong/rangda yang baru dibuat, harus dilakukan ritual penyucian (sakralisasi) untuk mendapatkan panugrahan sebagai sebagai tapakan bhatara (Suyasa,2012; Suyatra,2017

Dalam ritual tantrik ini diperagakan aktivitas berkomunikasi dengan kekuatan adikodrati, yang dipandang sebagai personifikasi dari Tuhan, Hyang Widhi. Komunikasi jenis ini digolongkan ke dalam jenis komunikasi non-human, yang berbeda dengan komunikasi antar manusia. Suamba (dalam Ardhi Wirawan, 2016), menyatakan pada dasarnya komunikasi non-human ini dapat terjadi antara seseorang dengan kekuatan adikodrati dalam konteks ritual keagamaan tertentu. Para pelaku ritual mengalami bava dan rasa, sebagai ciri komunikasi transcendental yang efektif.

Komunikasi Hindu berpeluang mengembangkan focus kajiannya pada komunikasi non-human, terutama ketika mempelajari model-model komunikasi antara manusia dengan kekuatan adikodrati yang bersifat gaib atau transcendental. Karena itu pengembangan komunikasi 
Hindu dapat diarahkan pada komunikasi antara ciptaan dengan sang pencipta. Misalnya dalam setiap ritual/upacara agama, yang selalu menggunakan bendabenda, suara-suara, dan isyarat-isyarat tertentu yang bersifat magis/rahasya. Fenomena ini dapat diidentifikasi dan diinterpretasikan sebagai komponenkomponen pembentuk komunikasi nonhuman yang bersifat sacral dan transcendental, didalamnya terkandung peristiwa komunikasi transcendental (Ardhi Wirawan, 2016).

Peneliti memandang salah satu ritual yang mengandung komponen pembentuk peristiwa komunikasi transcendental adalah prosesi ngereh bagi tapakan bhatara di Bali. Dalam kegiatan ritual diasumsikan terdapat sejumlah unsur komunikasi non-human, yakni (1) pelaku ritual (human); (2) kekuatan gaib, yang diyakini sebagai personifikasi dari Hyang Widhi (non-human) keduanya silih berganti dapat berperan sebagai komunikator dan komunikan; (3) mantra dan mudra sebagai pesan verbal dan nonverbal; (4) yantra dalam bentuk sarana upakara, mandala, dan kala sebagai media komunikasi transcendental. Semua penggambaran peristiwa komunikasi transcendental tersebut menjadi latar belakang dilakukan penelitian ini.

Banyak penelitian terdahulu dengan topik ritual magis ngerehang tapakan bhatara seperti yang telah dilakukan Niti Kurniasari (2013) , Suyasa (2012) dan Suyatra (2017), yang mengulas rangkaian aktvitas ritual, dan ketentuan aturan dan peraturan yang harus ditaati ( etika dan pengendalian diri). Namun belum ada kajian komunikasi transcendental tentang ritual ngereh tapakan bhatara. Dengan demikian penelitian ini menjadi penting dilakukan, dalam rangka pengembangan ilmu komunikasi agama, utamanya ilmu komunikasi Hindu.

Berdasarkan latar belakang masalah di atas, maka dapat dirumuskan permasalahan (1) Bagaimana peristiwa komunikasi transendental terjadi dalam konteks prosesi ngereh bagi tapakan bhatara di Bali ?" (2) komponen-komponen apa saja yang membentuk peristiwa komunikasi dalam konteks prosesi ngereh bagi tapakan bhatara di Bali ?"(3) Dalam konteks apa saja peristiwa komunikasi transendental itu berlangsung ? (4) Bagaimana efek komunikasi transendental terjadi dalam konteks prosesi ngereh bagi tapakan bhatara di Bali ?"

Sejalan dengan rumusan masalah di atas maka tujuan yang ingin dicapai dalam penelitian ini adalah dapat diidentifikasikan dan diinterpretasikan data tentang pola komunikasi transcendental, yang menggunakan media yantra, mantra, mudra, mandala, dan kala dalam konteks prosesi ngereh bagi tapakan bhatara di Bali.

Hasil penelitian ini diupayakan dapat dipublikasikan melalui jurnal ilmiah. Dengan demikian dapat digunakan sebagai sumbangan pemikiran bagi pengembangan ilmu komunikasi, terutama pengembangan teori-teori yang terkait dengan penelitian komunikasi transendental pada aktivitas ritual masyarakat beragama. Sekaligus pula dapat dijadikan input/bahan masukan bagi mereka yang tertarik atau memang terlibat dengan pelaksanaan ritual pada masyarakat beragama.

Dengan perkataan lain, dapat digunakan sebagai informasi ilmiah tentang komunikasi transcendental pada ritual yang dilakukan masyarakat beragama. Lebih khusus lagi, melalui penelitian ini dapat membuka wawasan tentang komunikasi 
dengan Tuhan dan manifestasi-Nya yang eksis dalam alam semesta, yang selama ini penelitian-penelitian bidang komunikasi hanya terfokus pada penelitian komunikasi antar manusia saja.

\section{Prosesi Ngereh Bagi Tapakan Bhatara Dalam Perspektif Teoritis dan Metodologis}

Untuk menjelaskan pola komunikasi transcendental pada prosesi ngereh bagi tapakan bhatara secara teoritis, agak berbeda dengan penelitian objektifkuantitatif, yang menggunakan teori sebagai landasan penelitian. Oleh karena penelitian ini bersifat interpretative-kualitatif (subjektif), dimana menurut Kuswarno (2004) peneliti seyogyanya membebaskan diri dari "tawanan" suatu teori. Walaupun demikian teori diperlukan sebagai pedoman untuk mengumpulkan data, agar sesuai dengan focus penelitian. Teori dikembangkan searah dengan penelitian yang sedang berlangsung agar sesuai dengan kenyataan di lapangan. Disadari bahwa penelitian kualitatif menekankan pada perspektif emik, yang bertitik tolak dari fakta menuju abstraksi yang lebih tinggi, bukan dari konsep atau teori ke data atau informasi.

Dalam hubungan ini, digunakan teori yang dianggap paling relevan dengan konteks dan focus penelitian tentang prosesi ngereh bagi tapakan bhatara, yakni teori fenomenalogi transcendental dari Husserl. Edmund Husserl adalah pendiri dan tokoh utama aliran filsafat fenomenalogi. la sangat tertarik dengan penemuan makna dan hakikat dari pengalaman. Berpendapat bahwa ada perbedaan antara fakta dan esensi dalam fakta atau ada perbedaan antara yang riil dan yang tidak riil. Disinilah fenomenalogi bertugas menjelaskan sesuatu dalam diri mereka (things in themselves), mengetahui apa yang masuk sebelum kesadaran, dan memahami makna dan esensinya dalam intuisi dan refleksi diri. Artinya dibutuhkan gabungan antara yang nyata dan yang ideal. Proses ini isebut "ideation". Dalam ideation ini, objek yang muncul dalam kesadaran bersatu dengan objek itu sendiri, untuk menghasilkan makna yang dijadikan dasar bagi pengetahuan. Dengan teori ini, dipelajari bentuk-bentuk pengalaman pelaku prosesi ngereh bagi tapakan bhatara dari sudut pandang para pelakunya. Tidak saja mengklasifikasi tindakan sadar yang dilakukan, namun juga memprediksi terhadap tindakan di masa datang sesuai dengan cara pelaku memaknai objek yang dialaminya.

Dalam rangka mengeksplorasi kajian ini digunakan unit-unit analisis sebagai berikut: (1) Kesengajaan (Intentionality). Untuk menemukan makna prosesi ngereh bagi tapakan bhatara akan dianalisis "aku" yang pelaku prosesi ngereh, yang berbeda dengan "aku" yang bukan pelaku prosesi ngereh. Konsekwensinya satu objek riil dapat menghasilkan berbagai persepsi, bergantung pada siapa yang mempersepsi, kapan waktu dipersepsi, dari sudut pandang bagaimana, latar belakang proses persepsi, memori, harapan, penilaian dan sintesis noemata (makna yang dibuat), memungkinkan pelaku prosesi ngereh membuka ingatannya kembali, walau telah lama dialaminya. Kesengajaan itu dibangun dengan beberapa konsep seperi identitas dan temporalitas (identity and temporality); simbolis dan intuitif; tekstur dan struktur; persepsi atau konsepsi; masalah waktu. (2) Noema dan Noesis. Noesis adalah bahan dasar pikiran dan roh (mind and spirit). Noesis menyadarkan pelaku prosesi ngereh akan makna ketika mereka mempersepsi, mengingat, menilai, dan mengingat dengan 
menggunakan noesis. Lawan dari noesis adalah noema. Menurut Husserl noema itu faitfully and in the light of perfect selfevidence (bersifat tetap dan disertai buktibukti yang akurat), contoh tapakan barong dan tapakan rangda mudah dibedakan berdasarkan bentuk dan kriterianya. Ada kaitan erat antara noema dengan noesis. Melihat fenomena sebagai noesis (berdasarkan makna yang ada padanya, bukan berdasarkan ciri-ciri phisik yang ada padanya. (3) Intuisi. Kemampuan membedakan "yang murni". Alat untuk mencapai esensi, dengan memisahkan yang biasa dari objek, untuk menemukan kemurnian yang ada padanya. (4) Intersubjektivitas. Faktor intersubjektivitas berperan besar dalam pembentukan makna. Ada kencendrungan membandingkan pengalaman seseorang dengan pengalaman orang lain. Term transcendental yang digunakan Husserl mengacu pada penentangan terhadap dogma-dogma yang ada.

\section{PEMBAHASAN}

Peristiwa Komunikasi Transendental Dalam Konteks Prosesi Ngereh Bagi Tapakan Bhatara Di Bali

Sebelum terjadi peristiwa komunikas transcendental, pengereh dan pelaku ritual lainnya yang ikut terlibat dalam prosesi ngereh pada tapakan bhatara di Bali, terlebih dahulu harus memenuhi kualifikasi kekuatan dan kesehatan phisik serta mental. Teguh pada tapa dan brata, keyakinan yang teguh pada kemahakuasaan Ida Bhatara, yang dipuja dan disungsung. Bagi orang yang baru pertama kali melakukannya, syarat sehat lahir dan batin sangat penting, karena cobaan dan godaan yang harus dihadapi beresiko sangat besar mengancam diri pelaku; jangan coba-coba membawa jimat sebagai benda pelindung diri, sebab dapat berakibat sangat fatal; keberanian dan keyakinan pada diri sendiri harus kuat, tidak boleh ragu-ragu; sikap pasrah dan lascarya merupakan senjata yang paling ampuh menghadapi ancaman rasa takut.

Rangkaian/tahapan ngereh bagi tapakan bhatara menjadi wahana bagi terjadinya proses komunikasi. Dalam setiap tahap ritual terjadi peristiwa komunikasi transcendental. Pertama, ketika manggala/ pemangku/sangging menjalankan upakara prayascita dan masuci terjadi proses komunikasi transcendental antara manggala/pemangku/sangging dengan ista dewata yang dipuja sampai dirasakan secara intuitif bahwa komunikasi telah berlangsung secara efektif sehingga proses prayascita dan penyucian berjalan sesuai pengharapan. Kedua, ketika manggala upacara/ pemangku/sangging menjalan upakara ngatep dan mintonin kembali terjadi proses komunikasi transcendental antara manggala upacara/pemangku/sangging dengan ista dewata. Jika terjadi komunikasi yang efektif, maka diyakini terjadi proses utphati (kelahiran) terhadap tapakan bhatara. Mulai saat itu dapat difungsikan sebagai personifikasi dari kesaktian/kekuatan gaib sanghyang siwa yang sedang didambakan oleh masyarakat pemuja-Nya/penyungsungNya. Ketiga, ketika manggala upacara/ pemangku/sangging menjalankan upakara pasupati dan ngerehang juga terjadi proses komunikasi transcendental, jika berjalan efektif, maka diyakini bahwa tapakan bhatara mendapat panugrahan kesaktian/ kasiddhian, setelah sanghyang siwa berkenan memasukkan kekuatan gaib, maka para penyungsung-Nya memiliki pengharapan penuh bahwa tapakan bhatara mampu menjadi pelindung yang aktif. 
Berdasarkan temuan penelitian di atas dapat dinyatakan bahwa peristiwa komunikasi transcendental bagi tapakan bhatara di Bali secara social regius telah melembagakan simbol satyam (kebenaran), siwam (kesucian), sundaram (keindahan) Sanghyang Widhi Wasa, dalam perwujudan tapakan bhatara. Umat Hindu secara kodrati sebagai makhluk sosial senantiasa menghendaki adanya perlindungan kesehatan, bebas dari mara bahaya dan segala jenis penyakit dari Ida Sanghyang Widhi Wasa, yang simbol perlindungan-Nya disungsung dalam bentuk tapakan bhatara. Semangat religiousitas setiap umat Hindu senatiasa terbangun melalui komunikasi transendal dengan simbol-simbol kesucian Ida Sanghyang Widhi, yang disthanakan pada tapakan bhatara.

\section{Komponen Komunikasi Transendental Dalam Konteks Prosesi Ngereh Pada Tapakan Bhatara Di Bali}

Data tentang komponen komunikasi transcendental dalam konteks prosesi ngereh pada tapakan bhatara di Bali yang dapat dikumpulkan di lapangan adalah pelaku prosesi (pengereh) dan kekuatan adikodrati/gaib (yang berperan sebagai komunikator dan komunikan secara bergantian). Mantra atau sehe yang diucapkan dan mudra yang dibuat secara mistis (berperan sebagai pesan), sarana upakara sebagai yantra atau media komunikasi.

$$
\text { Pelaku prosesi (pengereh) }
$$

hendaklan memenuhi syarat umum dan khusus, dan lulus kualifikasi kekuatan dan kesehatan phisik serta mental. Syarat umum tekun melaksanakan norma susila dan pengendalian diri. Syarat khusus menjalankan disiplin brata, tapa, yoga, semadi secara ketat. Lulus ujian kualilifikasi, semacam uji nyali di tempat-tempat angker atau kuburan, sebelum praktik menjadi pengereh yang sesungguhnya. Hal ini akan membentuk kepribadian yang suci lahir, batin, sabar, kuat, berani, dan yakin pada perlindungn Ida Bhatara.

Bagi orang yang baru pertama kali melakukannya, syarat sehat lahir dan batin sangat penting, karena cobaan dan godaan yang harus dihadapi beresiko sangat besar mengancam diri pelaku; jangan coba-coba membawa jimat sebagai benda pelindung diri, sebab dapat berakibat sangat fatal; keberanian dan keyakinan pada diri sendiri harus kuat, tidak boleh ragu-ragu; sikap pasrah dan lascarya merupakan senjata yang paling ampuh menghadapi ancaman rasa takut.

Komunikasi transcendental dikatakan efektif apabila tanda-tanda berupa ada secercah sinar yang memasuki pengereh/tapakan bhatara, atau tanda lain berupa adanya gerakan-gerakan pada tapakan bhatara tanpa disentuh. Itu ciri adanya kekuatan adikodrati, pesan yang disampaikan berupa bava dan rasa yang diterima pengereh/pelaku prosesi.

Manggala/Pemangku/Sangging, sebagai pelaku prosesi ngereh berdoa dengan menggunakan mantra atau sehe dan mudra, gerakan tangan seperti menari, yang biasa dilakukan pada kondisi suprasadar. Mantra dan mudra tersebut merupakan pesan verbal dan nonverbal yang disampaikan baik secara sadar atau di atas kesadaran.

Yantra adalah alat atau instrument berupa diagram mistik. Upakara/ bebantenan dibuat dari daun, bunga, air, buah-buahan, biji-bijian, yang disusun sedemikian rupa menyerupai diagram mistik. Mandala adalah ruang atau posisi yang dikuasai kekuatan adikodrati. Misalnya 
pada banten caru, ditempatkan pada mandala tengah, timur, selatan, barat, dan utara, yang memiliki kode warna, senjata, dewa dan bhuta tertentu pula. Kala adalah waktu yang tepat menjalankan ritual ngereh adalah tengah malam, pada tilem atau kajeng kliwon. Pada prosesi ngereh digunakan banten prayascita, banten pesucian, banten ngatep dan mintonan, banten pasupati dan ngereh, di tempat pada mandala/ruang yang tepat, dan kala atau waktu yang tepat pula.

Mandala atau tempat ngereh bagi tapakan bhatara biasanya dilakukan di kuburan pada kala atau waktu tilem atau pada hari keramat di malam hari. Dilakukan tepat pada tengah malam, pukul 23,00, diawali dengan komunikasi matur piuning, mengaturkan sesajen di atas tanah, termasuk mengaturkan caru yang diikuti penyamblehan kucit butuhan (babi jantan yang masih muda). Orang yang ditugaskan ngereh duduk berhadapan dengan tapakan bhatara. Di tengah antara orang dan tapakan ditempatkan banten/upakara,yang utama adalah darah babi jantan (getih satu temelung) yang ditaruh pada takir (semacam mangkok dari daun pisang).

Temuan penelitian di atas telah mengidentifikasi adanya seperangkat komponen komunikasi transcendental pada aktivitas ngereh bagi tapakan bhatara di Bali. Hal itu dilakukan untuk memenuhi tatanan sosial religious yang selalu dilakukan manakala penyungsung suatu pura mendapat perintah gaib untuk pertama kali membuat tapakan bhatara. Demikian juga ngereh bagi tapakan bhatara memberikan motivasi dan nilai-nilai pada tingkat rasa batin yang paling dalam.

Perlindungan keselamatan dan kesejahteraan diyakini oleh para penyungsung-Nya secara social psikologis dapat berfungsi untuk mengatasi konflik; membangun solidaritas masyarakat; mempersatukan dua prinsip yang bertentangan; memberikan kekuatan dan motivasi baru untuk hidup dalam masyarakat secara sehat. Selain itu, tapakan bhatara itu diyakini juga memberikan perlindungan manakala masyarakat menghadapi krisis hidup, misalnya berbagai perubahan tahap-tahap hidup manusia, seperti kelahiran, pubertas, perkawinan, dan kematian serta nasib sial, gangguan roh jahat dan lain-lain.

Demikianlah umat Hindu (Bali) meyakini bahwa prosesi ngereh tapakan bhatara merupakan serangkaian perbuatan keramat yang dilakukan pelaku ritual dengan mengunakan berbagai macam unsur atau komponen, yaitu waktu, tempat, alat-alat upacara serta orang-orang yang menjalankan upacara. Prosesi ngereh tapakan bhatara mempunyai fungsi tindakan komunikatif (berdoa) untuk mendapat karunia kekuatan, kesehatan, kesejahtraan dari Tuhan Yang Maha Pelindung dan Maha Pemurah.

\section{Konteks Komunikasi Transendental Ngereh Bagi Tapakan Bhatara Di Bal}

Konteks komunikasi transcendental ngereh bagi tapakan bhatara yang dapat didentifikasi yaitu : Pertama, konteks komunikasi antara manggala/pemangku/ sangging dengan ista dewata ketika menjalankan upakara prayascita. Konteks komunikasi yang dapat diidentifikasi adalah sikap duduk dalam posisi asana, mantra dan sehe mulai dari mohon penyucian diri, matur piuning agar ista dewata memberikan kekuatan peleburan mala, wighna, wisaya, ngayab prayascita. Konteks komunikasi ketika nedunang bhatara ista dewa dengan mantra utphati dan sthiti, kemudian 
menghaturkan pereresikan. Dilanjutkan dengan matur piuning dan mengaturkan sesajen di atas tanah, termasuk mengaturkan caru yang diikuti penyamblehan kucit butuhan (babi jantan yang masih muda).

Kedua, konteks komunikasi antara manggala/pemangku/sangging dengan ista dewata ketika menjalankan upakara ngatep dan mintonin. Konteks komunikasi yang dapat diidentifikasi adalah sikap duduk dalam posisi asana, mantra dan sehe mulai dari mohon kekuatan adikodrati bertemu dengan tapakan bhatara dan mohon pemantapan kekuatan itu selalu eksis pada tapakan bhatara.

Ketiga, konteks komunikasi antara manggala/pemangku/sangging dengan ista dewata ketika menjalankan upakara pasupati dan ngereh. Konteks komunikasi yang dapat diidentifikasi adalah sikap duduk dalam posisi asana, mantra dan sehe mulai dari mohon penyucian diri, matur piuning, kemudian pengereh bersemedi, seorang diri, teman-teman yang berjaga-jaga dari kejauhan namun masih di sekitar kuburan. Seirama dengan berjalannya waktu yang bertambah larut malam, suasana komunikasi transcendental terasa mencekam, intuisi batin bertambah mekar di tengah semilirnya angin malam membuat bulu kuduk berdiri, secara perlahan namun pasti, bisikan hati nurani mulai terdengar dalam batin/dalam keadaan supra sadar atau antara sadar dan di atas sadar dapat dilihat datangnya seberkas sinar memasuki diri pengereh atau tapakan bhatara yang sedang diusung atau ciri lain, yakni tapakan bhatara bergerak sendiri, seperti hidup,sama sekali tanpa digerakkan.

\section{Efek Komunikasi Transendental Pada Ritual Ngereh Tapakan Bhatara di Bali}

Bagi pelaku ngereh, efek komunikasi transcendental berupa : pengalaman/ pengetahuan panca indera/kognitif, pengalaman rasa suka atau tidak suka/afektif; tindak/perilaku komunikasi. Bagi pelaku ngereh pemula (baru pertama kali) terlibat langsung, pengetahuan indera yang takut yang gaib, mendengar suara gaib, mencium bau aneh, dan bersentuhan langsung dengan suasana yang mencekam pada suasana magis berada di kuburan pada tengah malam. Tentu merupakan merupakan sesuatu yang baru, yang lain daripada yang lain. Pengetahuan ini dialami oleh semua informan yang diwawancarai, sayang sekali data ini tidak dialami sendiri oleh peneliti, karena tidak berdasarkan data hasil observasi partisipan.

Pelaku ngereh yang mendapatkan pengetahuan afektif dari suasana ritual ngereh, juga pasti akan merasakan pengalaman yang sensasional, merasakan bulu kuduk berdiri, rasa senang dan takut campur aduk. Demikian pengakuan informan yang diterima. Ini disebut efek afektif. Demikian pula dengan pengalaman perilaku, tentu ini merupakan tindakan yang langka dialami terutama bagi pemula (baru pertama kali) melakukannya. Semua informan mengaku mendapat pengalaman bertindak yang sangat mistis.

Efek komunikasi transcendental adalah keyakinan bahwa tapakan bhatara telah suci dan sakti, layak dipuja dan dimohonkan perlindungan dari segala bentuk ganggungan yang menghalangi diperolehnya keselamatan dan kesejahteraan masyarakat. Dikatakan oleh informan bahwa ciri keberhasilan ritual ini adalah adanya kontak dengan alam gaib, berupa seberkas sinar yang jatuh tepat pada 
pemundutnya (pengusungnya). Orang yang mengusung itu, begitu dimasuki sinar, akan mengalami trance/kesurupan dan menarinari. Tanda lain yang biasa terjadi yang memberikan ciri keberhasilan ritual ini adalah apabila tapakan bhatara bergerakgerak atau bergoyang-goyang tanpa ada yang menyentuhnya. Ngereh bagi tapakan bhatara adalah sebuah ritual magis yang ditandai dengan adanya peristiwa kesurupan yang dialami pengusung tapakan bhatara, yang dilakukan dengan sengaja untuk membuktikan bahwa tapakan bhatara yang diupacarai telah memiliki kekuatan gaib (mepasupati), dan diyakini memiliki kekuatan/kesaktian untuk melindungi masyarakat penyungsungnya dari segala bentuk mara bahaya. Komunikasi transcendental memberikan pengetahuan dan pengalaman social religious baik secara kognitif, afektif, dan behavioral. Pengetahuan ini tentu saja sangat special bagi yang mengalaminya. Tidak semua umat Hindu dapat memperoleh pengalaman yang jarang terjadi. Melalui publikasi hasil penelitian ini, paling tidak memberikan informasi awal tentang adanya pengetahuan dan pengalaman yang spesifik dapat diperoleh dari prosesi ngereh bagi tapakan bhatara di Bali.

\section{PENUTUP}

\section{Simpulan}

Berdasarkan uraian di atas dapat disimpulkan hal-hal sebagai berikut.

1. Peristiwa komunikasi transcendental bagi tapakan bhatara di Bali secara social regius telah melembagakan simbol satyam (kebenaran), siwam (kesucian), sundaram (keindahan) Sanghyang Widhi Wasa, dalam perwujudan tapakan bhatara. Umat Hindu secara kodrati sebagai makhluk sosial senantiasa menghendaki adanya perlindungan kesehatan, bebas dari mara bahaya dan segala jenis penyakit dari Ida Sanghyang Widhi Wasa, yang simbol perlindungan-Nya disungsung dalam bentuk tapakan bhatara. Semangat religiousitas setiap umat Hindu senatiasa terbangun melalui komunikasi transendal dengan simbolsimbol kesucian Ida Sanghyang Widhi, yang disthanakan pada tapakan bhatara.

2. Komunikasi transcendental dikatakan efektif apabila tanda-tanda berupa ada secercah sinar yang memasuki pengereh/tapakan bhatara, atau tanda lain berupa adanya gerakan-gerakan pada tapakan bhatara tanpa disentuh. Itu ciri adanya kekuatan adikodrati, pesan yang disampaikan berupa bava dan rasa yang diterima pengereh/pelaku prosesi. Selain itu, ngereh bagi tapakan bhatara di Bali dilakukan untuk memenuhi tatanan sosial religious yang selalu dilakukan manakala penyungsung suatu pura mendapat perintah gaib untuk pertama kali membuat tapakan bhatara. Demikian juga ngereh bagi tapakan bhatara memberikan motivasi dan nilai-nilai pada tingkat rasa batin yang paling dalam.

3. Konteks komunikasi transcendental prosesi ngereh bagi tapakan bhatara berlangsung ketika mangala/pemangku/sangging menjalankan upakara prayascita; ketika mangala/pemangku/sangging menjalankan upakara ngatep dan mintonin; dan ketika mangala/pemangku/sangging menjalankan upakara pasupati dan ngereh. Hal ini menjadi tema budaya 
spiritual yang penting dalam kehidupan umat Hindu, terutama sebagai wahana menghubungkan diri dengan Ida Sanghyang Widhi yang telah diwujudkan melalui tapakan bhatara di pura.

4. Ngereh bagi tapakan bhatara adalah sebuah ritual magis yang ditandai dengan adanya peristiwa kesurupan yang dialami pengusung tapakan bhatara, yang dilakukan dengan sengaja untuk membuktikan bahwa tapakan bhatara yang diupacarai telah memiliki kekuatan gaib (mepasupati), dan diyakini memiliki kekuatan/ kesaktian untuk melindungi masyarakat penyungsungnya dari segala bentuk mara bahaya. Komunikasi transcendental memberikan pengetahuan dan pengalaman social religious baik secara kognitif, afektif, dan behavioral. Pengetahuan ini tentu saja sangat special bagi yang mengalaminya. Tidak semua umat Hindu dapat memperoleh pengalaman yang jarang terjadi. Melalui publikasi hasil penelitian ini, paling tidak memberikan informasi awal tentang adanya pengetahuan dan pengalaman yang spesifik dapat diperoleh dari prosesi ngereh bagi tapakan bhatara di Bali.

\section{DAFTAR PUSTAKA}

Basrowi dan Sukidin . 2002. Metode Penelitian Kualitatif Perspektif Mikro.Surabaya : Insan Cendekia Ibrahim, Abd.Syukur.1992. Panduan

Penelitian Etnografi Komunikasi.

Surabaya: Usaha Nasional Kuswarno.2011. Metodologi Penelitian Komunikasi Entografi Komunikasi, Suatu Pengantar, dan Contoh
Penelitiannya. Bandung : Widya Padjajaran.

Moleong, Lexy J. .2006. Metodologi

Penelitian kualitatif. Bandung: PT

Rosdakarya

Mulyana, Deddy. 2001. Metodologi

Penelitian Kualitatif : Paradigma Baru

IImu Komunikasi Dan IImu Sosial

Lainnya. Bandung: PT.Remaja Rosdakarya

Nala, I Gst. Ngurah, dan I.G.K.Adia Wiratmadja. 2012. Murddha Agama

Hindu.Denpasar : Upadasastra

Niti Kurniasari, Ni Luh Nyoman. 2013. Ngereh Ritual Magis Di Bali. Singaraja: Undiksha

Ngurah, I Gusti Made. 2011. Samhita Vacana Agama Hindu (Himpunan Naskah Dharma Vacana). Surabaya : Paramita

Rai Putra, Ida Bagus (Ed.). 2014.

Swastikarana Pedoman Ajaran Hindu Dharma. Denpasar: PT Mabhakti

Siwananda. 1993. All About Hindusm,( Alih bahasa ke dalam bahasa Indoesia : Intisari Agama Hindu oleh Yayasan Sanatana Dharmasrama). Surabaya : Paramita

Sugeng Pujilksono, . 2016. Metode Penelitian Komunikasi Kualitatif.

Malang : Intrans Publishing Jiwa Atmaja (Ed., 2007). Jejak Tantrayana Di Bali. Denpasar : Fak Sastra UNUD Suyasa, Wayan. 2012. Prosesi Ngereh Bagi Tapakan Bhatara Di Bali. (https//wayan suyasawebblog.blospot.com/2012/08/ prosesi ngereh bagi petapakan di bali.html?m=1)

Suyatra, Putu. 2017. Ngereh, Ritual Magis Mohon Restu Dari Tempat Pembakaran Mayat. Tabanan : Bali express 